\title{
Aldosterone to Renin Ratio as Screening Tool in Primary Aldosteronism
}

\author{
Authors \\ Katharina Schilbach ${ }^{1, ~ *}$, Riia Karoliina Junnila2, *, Martin Bidlingmaier ${ }^{1}$
}

\section{Affiliations}

1 Endocrine Research Unit, Medizinische Klinik und Poliklinik IV, Klinikum der Universität München, München, Germany

2 Laboratory for Molecular Pharmacology, Departement of Biomedical Sciences, Faculty of Health and Medical Sciences, University of Copenhagen, Denmark

\section{Key words}

hypertension, primary aldosteronism, immunoassays, interfering drugs

$\begin{array}{ll}\text { received } & 15.05 .2018 \\ \text { revised } & 18.07 .2018 \\ \text { accepted } & 08.08 .2018\end{array}$

\section{Bibliography}

DOI https://doi.org/10.1055/a-0672-0836

Published online: 30.8 .2018

Exp Clin Endocrinol Diabetes 2019; 127: 84-92

(c) J. A. Barth Verlag in Georg Thieme Verlag KG Stuttgart . New York

ISSN 0947-7349

\author{
Correspondence \\ Martin Bidlingmaier \\ Endocrine Research Unit \\ Medizinische Klinik und Poliklinik IV \\ Ziemssenstr. 1 \\ 80336 München \\ Germany \\ martin.bidlingmaier@med.uni-muenchen.de
}

\section{ABSTRACT}

Primary aldosteronism (PA) is a severe and often underdiagnosed form of secondary hypertension. Determining the aldosterone to renin ratio (ARR) in hypertensive patients has been shown to be a valuable screening test for identification of patients suffering from PA. Since the introduction of a more widespread ARR screening the number of PA patients significantly increased worldwide. Interpretation of ARR might be challenging: Several factors from posture to interfering drugs affect the ARR and need to be taken into account when collecting samples. In addition, the wide variety of available assay methods and lack of well-established cut-offs present a challenge to the clinician. This review discusses the usefulness and possible difficulties of ARR screening.

\section{Introduction}

In 2008 the WHO reported a $40 \%$ global prevalence for hypertension in adults ( $\geq 25$ of age). Hypertensive individuals, whose condition is caused by PA (or hyperaldosteronism), can be treated efficiently once a correct diagnosis has been reached. For a long time, hypokalemia was considered a key symptom of PA and the diagnosis was rarely taken into consideration in hypertensive patients when serum potassium was normal. However, more recent data confirm that a large proportion of patients affected from PA are normokalemic [1]. This group of patients remained un(der)diagnosed in the past. Consequently, extending search for PA to normokalemic patients had significant impact on prevalence of the disease: While prevalence of PA was believed to be less than $1 \% 20$ years ago, currently it is estimated that approximately $10 \%$ of all cases of hypertension are caused by PA [2]. It is very important to

Katharina Schilbach and Riia Karoliina Junnila contributed equally to this manuscript. identify patients with PA at an early stage since 1) their condition is, in many cases, more severe compared to patients suffering from essential hypertension, due to adverse effects caused by the high aldosterone concentrations in addition to the hypertension itself and 2) their treatment differs from other types of hypertension [37]. When the disease is caused by a unilateral aldosterone-producing adenoma (APA) or unilateral adrenal hyperplasia, adrenalectomy can potentially cure hypertension. In case of bilateral adrenal hyperplasia, management of hypertension is usually achieved by mineralocorticoid receptor antagonist treatment $[2,8]$.

PA is not only characterized by an increased aldosterone production but also decreased renin secretion. Already in 1981, determination of the ARR was suggested as a screening tool to identify PA patients among hypertensive individuals [9]. In the late 90s, a more widespread use of ARR as a screening tool to detect PA began and, in the following years, the number of cases diagnosed in several centers worldwide increased significantly [10]. Today, ARR is routinely used to screen hypertensive patients who could potentially 
have PA. The aim of this review is to discuss the "dos and don'ts" of ARR screening and to highlight potential pitfalls related to the use of various laboratory methods.

\section{Physiology behind the ARR}

The renin-angiotensin-aldosterone system (RAAS) is stimulated by hypotension and normalizes blood pressure by vasoconstriction as well as water and salt retention. Excessive activity of the system leads to hypertension. Renin is an enzyme that is secreted from the juxtaglomerular cells of the kidney in response to low blood pressure. Renin cleaves angiotensinogen into angiotensin I and thereby launches the RAAS. Angiotensin converting enzyme (ACE) leads to the production of Angiotensin II, which in turn stimulates production of aldosterone, a steroid hormone that increases blood pressure by renal sodium- and water retention and potassium excretion. Furthermore, it has a direct vasoconstrictive effect and stimulates the secretion of arginine-vasopressin, which also acts as a vasopressor agent [11]. In contrast to the physiological situation, where stimuli cause an increase in aldosterone secretion via high renin concentrations, the high aldosterone concentrations seen in PA patients in almost all cases are caused by excessive, autonomous production of aldosterone in the adrenal gland. The two main causes of the disease are unilateral aldosterone producing adenomas and bilateral hyperplasia (sporadic and familial cases). Furthermore, there are less common forms of hyperaldosteronism such as unilateral adrenal hyperplasia, aldosterone-producing adrenocortical carcinomas and ectopic aldosterone-secreting tumors [12-14]. In PA, the high aldosterone concentrations are accompanied by inadequately low renin, because renin secretion is suppressed as a consequence of the negative feedback loop. During the development of $\mathrm{PA}$, there is a continuum ranging from normal renin and aldosterone values in healthy individuals to clearly increased aldosterone with completely suppressed renin in overt PA. Between these extremes, the aldosterone to renin ratio continuously increases. At a time when total aldosterone is not yet considerably elevated, an elevated ARR already can indicate that - in relation to renin concentrations - aldosterone concentrations are inadequately high. This explains why the ARR is a more sensitive screening parameter than aldosterone alone, and why significantly more cases of PA are being detected since introduction of ARR screening [10].

\section{Who should be screened?}

As for all screening tests, pretest probability of the presence of a disease strongly determines negative and positive predicted values and thus efficacy of the ARR as a screening tool. Current guidelines limit the recommendation for screening to patients with an increased risk for PA. However, since PA is believed to be the most frequent cause of secondary hypertension, most recommendations place a high value on avoiding missing a PA diagnosis, while accepting the risk associated with additional diagnosis for false positive cases. The Endocrine Society recommends screening for PA in the following cases: Blood pressure of $>150 / 100 \mathrm{mmHg}$ taken on three different days, drug resistant hypertension (with at least three conventional antihypertensive drugs), controlled hypertension with $\geq$ four antihypertensive drugs, hypertension with spontaneous or di- uretic-induced hypokalemia, hypertension with adrenal incidentaloma, hypertension with a family history of hypertension or cerebrovascular events at a young age ( $<40$ years), people with both, hypertension and sleep apnea and all first-degree relatives of patients with PA [2]. Germline mutations that cause familial hyperaldosteronism account for $1-10 \%$ of all PA cases and new mutations continue to be discovered [15]. As atrial fibrillation (AF) seems to be overrepresented in PA it might be diagnostically important to screen patients with both, $\mathrm{AF}$ and hypertension $[3,16]$.

\section{Biological variation in aldosterone and renin}

Multiple biological factors affect circulating aldosterone and renin and need to be taken into account when 1) collecting samples for ARR screening and 2 ) interpreting results (for overview see - Table 1).

\section{Age and sex}

Plasma renin activity (PRA) and plasma renin concentration (PRC) as well as aldosterone concentrations decline with age, but, since renin might decrease more strongly, falsely elevated ARR sometimes is observed in elderly patients $[2,17,18]$. A population based study in 1347 healthy subjects suggested age-adjusted reference intervals for aldosterone, PRC and the ARR with the upper limit of normal for the ARR being approximately 10 points higher in older (55-74 years) as compared to the younger ( $25-54$ years) subjects [19]. They further reported sex related differences in both age

- Table 1 Influence of different biological factors on the ARR.

\begin{tabular}{|c|c|c|}
\hline Factor & $\begin{array}{l}\text { Influence } \\
\text { on ARR }\end{array}$ & Management \\
\hline Age $>50$ years & $\uparrow$ & $\begin{array}{l}\text { Under debate: adjustment of } \\
\text { cut-off values? }\end{array}$ \\
\hline Females & $\uparrow$ & $\begin{array}{l}\text { Under debate: adjustment of } \\
\text { cut-off values? }\end{array}$ \\
\hline Increased salt intake & $\leftrightarrow \downarrow$ & $\begin{array}{l}\text { No particular recommendation } \\
\text { concerning salt intake because } \\
\text { of the relatively small effect on } \\
\text { ARR. }\end{array}$ \\
\hline Restricted salt intake & $\uparrow$ & \multirow{2}{*}{$\begin{array}{l}\text { Potassium should lie within } \\
\text { normal ranges and should be } \\
\text { corrected before measurement. } \\
\text { No particular recommendation } \\
\text { concerning potassium intake. }\end{array}$} \\
\hline Hypokalemia & $\downarrow$ & \\
\hline $\begin{array}{l}\text { Increased potassium } \\
\text { intake }\end{array}$ & $\uparrow$ & \multirow{2}{*}{$\begin{array}{l}\text { Blood sampling in the morning } \\
\text { after patient has been up for at } \\
\text { least } 2 \mathrm{~h} \text {. Prior to the collection } \\
\text { the patient should be seated } \\
\text { for } 5-15 \text { min. }\end{array}$} \\
\hline Standing position & $\uparrow$ & \\
\hline Recumbency & $\uparrow$ & \multirow[t]{2}{*}{ No specific recommendations. } \\
\hline Renal impairment & $\downarrow$ & \\
\hline Stress & $\uparrow$ & $\begin{array}{l}\text { Prior to blood sampling the } \\
\text { patient should rest (in a seated } \\
\text { position) for } 5-15 \text { min and } \\
\text { additional stress should be } \\
\text { avoided. }\end{array}$ \\
\hline
\end{tabular}

$\uparrow$ increased (false positive ARR). $\downarrow$ decreased (false negative ARR). $\leftrightarrow$ No or minor/negligible impact on ARR. 
groups with higher upper ARR limits in females. This confirms earlier and recent observations in healthy and hypertensive subjects, where females had higher ARR than males [20,21]. Several studies suggest that this is due to regulatory effects of estrogen, progesterone and testosterone on the RAAS [22, 23]. In healthy women, both PRA and aldosterone concentrations have also been shown to be influenced by the menstrual cycle [24]. However, as both parameters increase from the follicular to the luteal phase, the ARR remains unchanged. The same observation has been made in female patients with low-renin hypertension: Although the ARR tended to be higher in the second part of the menstrual cycle, these changes did not reach significance [25]. Nonetheless, there may be individual cases in which significant changes of the ARR occur throughout the menstrual cycle: In a study with healthy women, 2 out of 19 had an increased ARR in the luteal phase if PRC was used to calculate the ARR [26]. In the same subjects no significant changes of the ARR could be detected using PRA.

Until today, no study formally investigated the impact of ageand sex-adjusted reference intervals on sensitivity and specificity of ARR screening for PA. Considering the evidence for an impact of age and sex on ARR this might, however, be of clinical importance and further studies are desirable.

\section{Circadian variation}

Both, renin and aldosterone, show circadian variation with peaks in the morning and declining values in the afternoon and the ARR has also been shown to vary with the time of day in hypertensive patients $[27,28]$. The latter study used PRA to calculate ARR. However, a more recent study - using PRC - did not confirm this finding in healthy subjects [19]. Generally, the potential effect of sampling time alone on the ARR seems to be small compared to the much stronger effects of posture, stress, drugs and potassium. Nevertheless, as most of the studies investigate the diagnostic cut-off for the ARR, for reasons of consistency blood sampling should preferably be done in the morning. In this context it is important to note that current guidelines recommend that samples should be taken at least $2 \mathrm{~h}$ after getting up [2].

\section{Salt intake}

Restricting dietary salt leads to an increase in aldosterone and renin whereas a salt load results in their suppression. Literature does not agree whether or how this affects the ARR. The Endocrine Society guideline warns that high dietary salt intake may lead to false positive ARR values [2]. In contrast, two studies found increased sodium intake to negatively correlate with ARR: In normotensive individuals, before and after a 3 -day salt load $(9 \mathrm{~g} \mathrm{NaCl} /$ day in addition to normal diet) the ARR was found to be unchanged when using PRA but decreased using PRC [29]. In hypertensive patients a negative correlation between ARR and natriuresis, an indicator of salt consumption, has been shown, suggesting that higher salt intake could lead to a decreased ARR [30]. However, the overall effect seems to be small, and recent recommendations suggest liberalizing rather than restricting sodium intake [2].

\section{Plasma potassium}

It is important to know the patient's potassium status when determining ARR. Hypokalemia is associated with decreased aldoster- one concentrations, possibly combined with increased renin. Therefore, hypokalemia could lead to false negative ARRs in individuals with PA [31]. Accordingly, guidelines recommend correction of hypokalemia with oral potassium supplementation before a blood sample is taken to determine the ARR. However, particularly in patients with PA, correction of hypokalemia can be challenging. Analysis in our own cohort revealed that $52 \%$ (13 out of 25) of the PA patients received potassium substitution (105.4+/-91.1 mval per day) during the diagnostic procedure, but $69.2 \%$ of these patients remained hypokalemic despite substitution (serum K 2.82+/-0.21 mmol/l) [32].

\section{Posture}

The Endocrine Society guideline recommends that an ARR sample is collected after the patient has been out of bed for a minimum of $2 \mathrm{~h}$ and seated for 5-15 min right before drawing blood [2]. Several studies have investigated the impact of posture on aldosterone and renin and their consequences for ARR. In one study with patients with borderline essential hypertension, the first sample was collected after $30 \mathrm{~min}$ in supine position followed by the second one after $30 \mathrm{~min}$ in standing position. During standing, aldosterone increased more substantially than PRA, leading to an elevated ARR. This has also been shown in other studies [33,34]. After four hours of ambulation ARR was decreased compared to overnight recumbency, both, in patients with PA and essential hypertension [27]. Change of position, from sitting to lying (for one hour) resulted in a decreased ARR in PA as well as in essential hypertension, although the difference reached significance only in the latter group [35]. A recent study showed that ARR in seating position is fairly correlated to ARR in supine and upright position in hypertensive patients. Due to the discrepant findings from the published studies it is difficult to predict how exactly posture will affect ARR determinations. Therefore, we suggest compliance with recommendations from the Endocrine Society guidelines in order to get comparable data.

\section{Renal impairment}

In PA and other forms of hypertension renal damage is caused by the elevated blood pressure but also by high concentrations of angiotensin II and aldosterone, both of them promoting vascular fibrosis [7, 36-39]. Nevertheless, in most patients with PA, creatinine clearance is significantly increased compared to patients with essential hypertension as well as in healthy controls [40]. This might be due to relative renal hyperfiltration caused by increased glomerular hydrostatic pressure and reduced afferent resistance [41]. These pathophysiological processes contribute to decreased renin secretion from the juxtaglomerular apparatus. Interestingly, in patients with PA, higher PRC may indicate a more severe renal damage [40]. This renin escape (from aldosterone suppression) is most likely induced by progressive glomerular hypoperfusion due to persisting vascular changes. In terms of diagnosing PA by use of ARR the impact of renal damage on renin concentrations can cause problems: Increased PRC or PRA, respectively, can lead to falsely low ARR values, thus masking PA [42]. 


\section{Stress}

It has been shown that stress might lead to an ACTH-induced aldosterone hypersecretion and thus an elevated ARR: Following the application of an ultralow-dose of ACTH $(0.03 \mu \mathrm{g}), 30$ hypertensive patients $(27 \%)$ had a significant increase in aldosterone without increase of cortisol. [43]. The authors speculate that an increased responsiveness of the zona glomerulosa is the underlying mechanism. Since stress increases aldosterone but not renin, falsely elevated ARRs can be observed [44-46]. In consequence, samples must be taken under resting conditions, and care must be taken to avoid stress during sampling.

\section{Interference by drugs}

Use of several drugs is known to alter aldosterone and renin, and possibly lead to a false positive or negative ARR. Most - although not all - of these interfering drugs are antihypertensive agents. Of course it is recommended to withdraw - whenever clinically possible - the drugs with the greatest influence on the ARR to obtain unbiased results for aldosterone and renin and, in consequence, the calculation of the ARR. When interfering drugs are stopped, most of the patients will need alternative therapy to control blood pressure. Recommended alternative preparations with no or negligible impact on ARR are non-dihydropyridines (i. e. verapamil), $\alpha-1$ blockers (i. e. doxazosin, urapidil, prazosin) or the direct smooth muscle relaxant hydralazine [2]. Moxonidine has also been shown not to significantly influence the ARR [47]. However, interrupting an established antihypertensive medication for ARR screening potentially has severe side effects and may often not be feasible at all. In such cases, correct interpretation of ARR can be difficult or even impossible, but knowing how the different types of drugs can affect the ARR certainly helps to avoid misinterpretation. For example, if the ARR is below the cut-off even when the concomitant medication is known to significantly lower renin and thus elevate the ARR (e. g. in a patient taking a beta blocker), the diagnosis of PA is unlikely. In contrary, if a patient is on diuretics or ACE inhibitors drugs known to eventually decrease ARR - an increased ARR makes the diagnosis of PA even more likely. In the following we will discuss in detail the impact of the various types of medications on the ARR; a summary of the findings is also provided in $>$ Table 2 .

\section{Interference by antihypertensive drugs}

Among the antihypertensive drugs aldosterone antagonists (spironolactone, eplerenone) and potassium-sparing diuretics (triamterene, amiloride) have the strongest lowering impact on the ARR and therefore should be withdrawn at least 4 weeks before measurement $[2,48]$. Loop diuretics (i. e. furosemide and torsemide), thiazide diuretics/thiazide-like diuretics (i. e. hydrochlorothiazide, chlorothiazide, chlorthalidone and indapamide) and dihydropyridines (calcium channel blockers such as amlodipine, nifedipine and lercanidipine) should not be taken at least 2 week prior to measurement as they have been shown to increase PRC and PRA and thus decrease the ARR $[2,48,49]$. In case of dihydropyridines some studies did not show an increase in PRA with unaltered ARR, however, withdrawing the medication may improve the diagnostic value of the ARR [50]. A less pronounced decrease of the ARR can be observed with angiotensin converting enzyme (ACE) inhibitors (i. e. ramipril, captopril) and angiotensin II receptor agonists $\checkmark$ Table 2 Influence of drugs on the ARR.

\begin{tabular}{|c|c|c|}
\hline Drug & $\begin{array}{l}\text { Influence } \\
\text { on ARR }\end{array}$ & Management \\
\hline \multicolumn{3}{|l|}{ Major influence on the ARR } \\
\hline Aldosterone antagonists & $\downarrow$ & $\begin{array}{l}\text { Stop taking medication } \\
\text { for } 4 \text { weeks. }\end{array}$ \\
\hline Potassium sparing diuretics & $\downarrow$ & $\begin{array}{l}\text { Stop taking medication } \\
\text { for } 4 \text { weeks. }\end{array}$ \\
\hline Potassium wasting diuretics & $\downarrow$ & $\begin{array}{l}\text { Stop taking medication } \\
\text { for } 4 \text { weeks. }\end{array}$ \\
\hline $\begin{array}{l}\text { Antidepressant agents } \\
\text { (see text) }\end{array}$ & $\downarrow$ & $\begin{array}{l}\text { Stop taking medication } \\
\text { for } 4 \text { weeks. }\end{array}$ \\
\hline $\begin{array}{l}\text { Drospirenone-containing oral } \\
\text { contraceptives }\end{array}$ & $\uparrow$ & $\begin{array}{l}\text { Stop taking medication } \\
\text { for } 4 \text { weeks. }\end{array}$ \\
\hline B-Blocker & $\uparrow$ & $\begin{array}{l}\text { Stop taking medication } \\
\text { for } 2 \text { weeks. }\end{array}$ \\
\hline Central alpha 2 agonists & $\uparrow$ & $\begin{array}{l}\text { Stop taking medication } \\
\text { for } 2 \text { weeks. }\end{array}$ \\
\hline liquorice & $\uparrow \downarrow$ & $\begin{array}{l}\text { Stop consuming for } 4 \\
\text { weeks. }\end{array}$ \\
\hline \multicolumn{3}{|l|}{ Minor influence on the ARR } \\
\hline ACE-inhibitor & $\downarrow$ & $\begin{array}{l}\text { Stop taking medication } \\
\text { for } 2 \text { weeks. }\end{array}$ \\
\hline $\begin{array}{l}\text { Angiotensin II receptor } \\
\text { antagonists }\end{array}$ & $\downarrow$ & $\begin{array}{l}\text { Stop taking medication } \\
\text { for } 2 \text { weeks. }\end{array}$ \\
\hline $\begin{array}{l}\text { Calcium channel blockers } \\
\text { (dihydropyridines) }\end{array}$ & $\downarrow(\leftrightarrow)$ & $\begin{array}{l}\text { Stop taking medication } \\
\text { for } 2 \text { weeks. }\end{array}$ \\
\hline Thiazide diuretics & $\downarrow$ & $\begin{array}{l}\text { Stop taking medication } \\
\text { for } 2 \text { weeks. }\end{array}$ \\
\hline Renin inhibitors & $\begin{array}{l}\uparrow \downarrow \\
\text { (dependent } \\
\text { on method) }\end{array}$ & $\begin{array}{l}\text { Stop taking medication } \\
\text { for } 2 \text { weeks. }\end{array}$ \\
\hline \multicolumn{3}{|l|}{ Very low influence on the ARR } \\
\hline oral contraceptives & $\uparrow$ & $\begin{array}{l}\text { Stop taking medication } \\
\text { for } 1 \text { week (only if } \\
\text { alternative effective } \\
\text { contraception is available) }\end{array}$ \\
\hline ASS & $\uparrow$ & $\begin{array}{l}\text { Stop taking medication } \\
\text { for } 2 \text { weeks. }\end{array}$ \\
\hline Verapamil & $\leftrightarrow$ & $\begin{array}{l}\text { Medication can be } \\
\text { continued or used as } \\
\text { alternative drug if other } \\
\text { antihypertensive drugs } \\
\text { have to be discontinued } \\
\text { for ARR measurement. }\end{array}$ \\
\hline Hydralazine & $\leftrightarrow$ & \\
\hline Prazosin & $\leftrightarrow$ & \\
\hline Doxazosin & $\leftrightarrow$ & \\
\hline Moxonidine & $\leftrightarrow$ & \\
\hline
\end{tabular}

(i. e. candesartan, valsartan) $[48,49,51]$. Both classes of drugs lead to a decrease of aldosterone leading to loss of sodium and water and a subsequent increase of PRC and PRA. Medication intake should be stopped at least 2 week before measurement [2]. This also applies to $\beta$-blockers (i. e. bisoprolol, metoprolol, atenolol) and 
central $\alpha$ - 2 agonists (i. e. $\alpha$-methyldopa, clonidine), which lead to a false positive ARR due to a marked decrease of PRC and PRA and a slight decrease of aldosterone $[48,49,52,53]$. In case of renin inhibitors (aliskiren), which also has to be paused for at least 1 week, the influence on the ARR depends on the procedure of renin-measurement: measuring PRC will result in increased values and a false negative ARR whereas PRA is decreased resulting in an increased ARR $[54,55]$.

\section{Other interfering drugs and substances}

In addition to antihypertensive drugs, other types of medications and plant substances have been found to alter the ARR. Nonsteroidal anti-inflammatory drugs such as aspirin reduce PRA and lead to false positive ARR values. Even small doses of $100 \mathrm{mg}$ can influence the measurement and should not be taken 1 week prior to measurement if PRA is measured [56]. Use of serotonin uptake inhibitors (SSRIs) has been shown to greatly increase PRA and PRC and therefore decrease ARR [57]. Even though the study was conducted in normotensive depressed patients, the potential for false negative ARRs in PA patients on antidepressant medication should not be ignored. A 4-week pause would be suggested but might be difficult to realize in depressive patients with hypertension. Ideally, measurement of aldosterone and renin is conducted before initializing treatment with SSRIs in depressive and hypertensive patients. In women receiving hormone replacement therapy or oral contraceptives, aldosterone is increased and PRC (but to a lesser extent PRA) is decreased. As a consequence, ARR can be markedly increased (up to 2 -fold) [19, 22, 23]. In young healthy normotensive women on oral contraceptives, the influence on aldosterone and renin is further modulated by the progestin component, renin assay method and route of administration [26]. Since drospirenone-containing oral contraceptives have been shown to lead to false positive screening test results, they should be paused at least 4 weeks before ARR-measurement [58]. Recently, products containing desogestrel and gestodene have been demonstrated to haven an even greater impact on ARR than those with drospirenon [59]. Interestingly, treatment with subdermal etonogestrel does not seem to change aldosterone concentrations, PRC, PRA and the ARR [60]. Patients who regularly eat liquorice (glycyrrhetinic acid) can develop pseudoaldosteronsim (apparent mineralocorticoid excess syndrome). Glycyrrhetinic acid inhibits the conversion of cortisol to cortisone through inhibition of the 11-beta-hydroxysteroid dehydrogenase type 2 (11-beta-HSD2). Non-converted cortisol activates the mineralocorticoid receptor and leads to increased sodium concentrations, water retention and hypertension. Furthermore, a decrease in PRA and in aldosterone concentrations occurs [61]. In normal subjects ARR decreased following acute liquorice ingestion [62]. However, the net effect of liquorice consumption on ARR may depend on several factors. Generally, as both hormones tend to be very low, the calculation of ARR under chronic liquorice ingestion may be misleading. Therefore, for diagnostic purposes patients should be advised to stop the intake 4 weeks before aldosterone and renin measurements [2].

\section{Analytical Variability - The Impact of Assay Methods on ARR}

There is a wide range of assay combinations being used to determine aldosterone and renin for calculation of ARR. Unfortunately, there is considerable lack of standardization between the different assays, leading to significant discrepancies in obtained results [63]. Immunoassays have traditionally been used to measure concentrations of aldosterone, and still are most frequently used. Antibody specificity, sensitivity and the use - or the lack of - extraction steps have been shown to have considerable impact on the measured concentrations [64]. During the last years new automated immunoassays became available, which show good correlation to older analytical methods (i. e. radioimmunoassays) $[65,66]$. The more recently developed assays based on mass spectrometry certainly bear the potential to solve some of the assay related problems in determination of aldosterone [67-70]. The results from specialized laboratories in the field are promising. However, if and to what extent LC/MS-MS assays can improve inter-laboratory agreement of the measured concentrations remains to be determined and might only be known after such methods become broadly available and more frequently used under routine conditions. Data from recent external quality assessment schemes (e. g. Reference Institute for Bioanalytics at https://www.rfb.bio/) illustrate that discrepancies between laboratories can remain even when using mass spectrometry. In this context, the availability and quality of the materials used for calibration remains an issue [71]. Another major contributor to the assay-related discrepancies in ARR values is the parallel use of assays that measure PRA and actual renin concentration or "direct renin" (PRC). Measurement of PRA adds another variable since it depends on patients' angiotensinogen concentrations, but also allows a more sensitive measurement by extension of incubation time. Measurement of PRC is technically easier, less affected by individual laboratories expertise and thus more standardized [72]. A handful of studies have compared the different assay combinations and especially the consequence of using PRA vs. PRC. The results are rather contradictory - while some authors conclude that ARR is very similar whether it is based on PRA or PRC others state that diagnosis may depend on whether PRA or PRC was used to determine the ARR [29,73-76]. Generally, external quality assessment schemes for laboratories suggest better laboratory agreements for laboratories using PRC as opposed to laboratories using PRA (as an example see the quarterly results from the German external quality assessment scheme at https://www.rfb.bio/). The smaller differences between measurements in different laboratories using the same analytical method certainly provide a major advantage of measurement of PRC over PRA as it might facilitate use of uniform cut-offs.

\section{Defining the cut-off}

Owing to the wide variety of aldosterone and renin assays being used to determine the ARR, the use of both PRC and PRA and the inconsistency in units that are used to report the ARR, there is no universal cut-off above which PA must be suspected. The various cut-offs reported are based on different assay combinations and, 
- Table 3 ARR: Published cut-offs from different studies between 2000-2015.

\begin{tabular}{|c|c|c|c|c|c|c|}
\hline Cut-off based on ${ }^{*}$ / used in ${ }^{*}{ }^{*}$ which cohort? & $\mathbf{n}$ & ARR cut-off & Units & Aldosterone cut-off & Reference & Year \\
\hline Hypertensive patients & 160 & $3,7^{*}$ & $(\mathrm{ng} / \mathrm{dL}) /(\mu \mathrm{U} / \mathrm{mL})$ & $\mathrm{N} / \mathrm{S}$ & [35] & 2014 \\
\hline Hypertensive patients & 53 & $19^{*}$ & $(\mathrm{pg} / \mathrm{mL}) /(\mu \mathrm{Ul} / \mathrm{mL})^{* * *}$ & $\mathrm{~N} / \mathrm{S}$ & [39] & 2015 \\
\hline Hypertensive patients without interfering medication & 152 & $1,2^{*}$ & $(\mathrm{ng} / \mathrm{dL}) /(\mathrm{mlU} / \mathrm{mL})$ & $\mathrm{N} / \mathrm{S}$ & [65] & 2015 \\
\hline Hypertensive patients & 100 & $2,7^{* *}$ & $(\mathrm{ng} / \mathrm{dL}) /(\mathrm{mlU} / \mathrm{mL})$ & $\mathrm{N} / \mathrm{S}$ & [66] & 2015 \\
\hline Hypertensive patients & 160 & $5,7^{*}$ & $(\mathrm{ng} / \mathrm{dL}) /(\mathrm{ng} / \mathrm{L})$ & $\mathrm{N} / \mathrm{S}$ & [35] & 2014 \\
\hline Hypertensive patients & 350 & $20 * *$ & $(\mathrm{ng} / \mathrm{dL}) /(\mathrm{ng} / \mathrm{mL} / \mathrm{h})$ & $>15 \mathrm{ng} / \mathrm{dl}$ & [81] & 2000 \\
\hline Hypertensive patients & 305 & $25^{* *}$ & $(\mathrm{ng} / \mathrm{dL}) /(\mathrm{ng} / \mathrm{mL} / \mathrm{h})$ & $>16 \mathrm{ng} / \mathrm{dl}$ & {$[82]$} & 2000 \\
\hline Hypertensive patients on medication & 90 & $100 * *$ & $(\mathrm{ng} / \mathrm{dL}) /(\mathrm{ng} / \mathrm{mL} / \mathrm{h})$ & $\mathrm{N} / \mathrm{S}$ & [83] & 2001 \\
\hline Hypertensive patients in 4 different centers & 5727 & $20 * *$ & $(\mathrm{ng} / \mathrm{dL}) /(\mathrm{ng} / \mathrm{mL} / \mathrm{h})$ & $>15 \mathrm{ng} / \mathrm{dl}$ & [10] & 2004 \\
\hline Hypertensive patients in 4 different centers & 6650 & $25^{* *}$ & $(\mathrm{ng} / \mathrm{dL}) /(\mathrm{ng} / \mathrm{mL} / \mathrm{h})$ & $\mathrm{N} / \mathrm{S}$ & [10] & 2004 \\
\hline Hypertensive patients in 4 different centers & 860 & $30 * *$ & $(\mathrm{ng} / \mathrm{dL}) /(\mathrm{ng} / \mathrm{mL} / \mathrm{h})$ & $\mathrm{N} / \mathrm{S}$ & [10] & 2004 \\
\hline Hypertensive patients in 4 different centers & 9580 & $40^{* *}$ & $(\mathrm{ng} / \mathrm{dL}) /(\mathrm{ng} / \mathrm{mL} / \mathrm{h})$ & $>15 \mathrm{ng} / \mathrm{dl}$ & [10] & 2004 \\
\hline Hypertensive patients ambulatory & 62 & $13,1^{*}$ & $(\mathrm{ng} / \mathrm{dL}) /(\mathrm{ng} / \mathrm{mL} / \mathrm{h})$ & $\mathrm{N} / \mathrm{S}$ & [27] & 2005 \\
\hline Hypertensive patients recumbent & 62 & $35^{*}$ & $(\mathrm{ng} / \mathrm{dL}) /(\mathrm{ng} / \mathrm{mL} / \mathrm{h})$ & $\mathrm{N} / \mathrm{S}$ & [27] & 2005 \\
\hline Hypertensive patients & 160 & $30^{*}$ & $(\mathrm{ng} / \mathrm{dL}) /(\mathrm{ng} / \mathrm{mL} / \mathrm{h})$ & $\mathrm{N} / \mathrm{S}$ & [35] & 2014 \\
\hline Hypertensive patients & 100 & $30 * *$ & $(\mathrm{ng} / \mathrm{dL}) /(\mathrm{ng} / \mathrm{mL} / \mathrm{h})$ & $\mathrm{N} / \mathrm{S}$ & [66] & 2015 \\
\hline Healthy males, age 25 - 54 & 416 & $14,2^{*}$ & $(\mathrm{ng} / \mathrm{L}) /(\mathrm{ng} / \mathrm{L})$ & $\mathrm{N} / \mathrm{S}$ & [19] & 2010 \\
\hline Healthy females, age 25-54 & 618 & $20,3^{*}$ & $(\mathrm{ng} / \mathrm{L}) /(\mathrm{ng} / \mathrm{L})$ & $\mathrm{N} / \mathrm{S}$ & [19] & 2010 \\
\hline Healthy males, age 55 - 74 & 130 & $22,4^{*}$ & $(\mathrm{ng} / \mathrm{L}) /(\mathrm{ng} / \mathrm{L})$ & $\mathrm{N} / \mathrm{S}$ & [19] & 2010 \\
\hline Healthy females, age 55-74 & 183 & $25,5^{*}$ & $(\mathrm{ng} / \mathrm{L}) /(\mathrm{ng} / \mathrm{L})$ & $\mathrm{N} / \mathrm{S}$ & [19] & 2010 \\
\hline Hypertensive patients & 465 & $750 * *$ & $(\mathrm{pmol} / \mathrm{L}) /(\mathrm{ng} / \mathrm{mL} / \mathrm{h})$ & $\mathrm{N} / \mathrm{S}$ & [84] & 2000 \\
\hline
\end{tabular}

to further complicate the situation, have been validated and tested in different patient populations. Many studies are limited to very specific patient populations, while others report ARR values in the general population $[35,51,77]$. An overview illustrating the wide spectrum of cut-off values reported and used from different studies is given in $>$ Table 3. The guidelines of the Endocrine Society from 2016 list a number of cut-offs being used and showed that cut-offs between 20 and $40(\mathrm{ng} / \mathrm{dl}) /(\mathrm{ng} / \mathrm{ml} / \mathrm{h})$ are most commonly used in ambulatory patients [2]. However, they did not recommend one specific cut-off to be used in daily clinical practice. Because of the lack of standardization between assay methods and the significant differences between the results from different laboratories, each assay manufacturer or each laboratory ideally should determine their own method specific cut-off, but this might be difficult to achieve.

It should be kept in mind that the cut-off - even when validated for the assay combination in use so that analytical variability can be ignored - does not represent a clear-cut distinction between patients with and without PA. It rather represents a compromise between sensitivity and specificity of the screening test to detect PA. If it is considered important to detect all cases of PA, the cutoff must be lower. If false positive cases need to be avoided, it might be appropriate to increase the cut-off. Furthermore, when comparing different studies it is important to realize that any cut-off derived to distinguish PA patients from normotensive individuals (as an example see reference [78]) inherently is associated with higher specificity and sensitivity than a cut-off derived to distinguish between PA patients and patients with essential hypertension. The latter, however, obviously is the more interesting scenario for clinical routine [65].

As shown in $>$ Table 3 some of the earlier studies used an aldosterone concentration exceeding $15 \mathrm{ng} / \mathrm{dl}$ as an additional diagnostic criterion, while others demonstrated that this cut-off might be too high and therefore patients with PA could be missed [79]. Although many clinicians might tend to look for PA mainly in cases with moderate to high aldosterone concentrations, the use of a specific aldosterone cut-off is currently not suggested by the Endocrine Society guideline[2]. More data from prospective studies are warranted to finally clarify the impact of such an additional criterion on sensitivity and specificity during screening.

Based on the experience in our clinic and within the German Conn Registry we use an ARR cut-off of $12(\mathrm{pg} / \mathrm{ml}) /(\mathrm{mU} / \mathrm{l})$ based on an aldosterone concentration above $50 \mathrm{pg} / \mathrm{ml}$ (as measured by an automated immunoassay). Note: To convert renin from $\mathrm{mU} / \mathrm{L}$ to $\mathrm{ng} / \mathrm{L}$ multiply by 1.66 . To convert aldosterone from $\mathrm{ng} / \mathrm{dL}$ to pmol/L, multiply by 27.7 .

\section{Future directions}

Despite its challenges, determining the ARR is a valuable tool in identification of PA patients among hypertensive individuals. PA is a common cause of secondary hypertension and the consequences of undiagnosed or late diagnosed disease and the resulting economic impact justify (repeated) ARR determination in the defined group of patients. Furthermore, testing is simply done and without 
risk for the patient and there are different effective treatment options for patients suffering from PA [2].

It is however important to keep in mind that ARR is a screening method and one of the common confirmatory tests (saline infusion test, captopril test, fludrocortisone suppression and oral sodium loading) is required for final diagnosis. In cases with ambiguous results a second test (out of those four) will be needed to confirm the diagnosis.

To increase the predictive significance of the ARR it is mandatory to take into account the influencing factors (such as age, gender, concomitant medication and renal function) in every determination of the ARR. After considering the risks and benefits for the individual patient ARR-influencing drugs should be paused (as suggested in > Table 2) or replaced. Ideally, testing should be performed under identical conditions: blood sampling in the morning, after the patient has been up for $2 \mathrm{~h}$ and after a $10 \mathrm{~min}$ rest in a seated position. Furthermore it is important to know the analytical procedure for aldosterone, PRA and PRC, respectively, and to define a minimal aldosterone concentration.

Looking towards the future, more uniformity in assay methods and consensus on the appropriate ARR cut-offs will hopefully further improve the clinical value of this powerful screening tool. Considering the available data definition of age- and sex-specific ARR cut-offs is highly desirable. As recent studies pointed out the influence of aldosterone-producing adenomas on plasma prorenin concentrations might become a further component of the diagnostic approach of PA [80].

\section{Conflict of Interest}

No conflict of interest has been declared by the authors.

\section{References}

[1] Rossi GP, Bernini G, Caliumi C et al. A prospective study of the prevalence of primary aldosteronism in 1,125 hypertensive patients. J Am Coll Cardiol 2006; 48: 2293-2300

[2] Funder JW, Carey RM, Mantero F et al. The management of primary aldosteronism: Case detection, diagnosis, and treatment: An endocrine society clinical practice guideline. J Clin Endocrinol Metab 2016; 101: 1889-1916

[3] Born-Frontsberg E, Reincke M, Rump LC et al. Cardiovascular and cerebrovascular comorbidities of hypokalemic and normokalemic primary aldosteronism: Results of the German Conn's Registry. J Clin Endocrinol Metab 2009; 94: 1125-1130

[4] Mulatero P, Monticone S, Bertello C et al. Long-term cardio- and cerebrovascular events in patients with primary aldosteronism. J Clin Endocrinol Metab 2013; 98: 4826-4833

[5] Savard S, Amar L, Plouin PF et al. Cardiovascular complications associated with primary aldosteronism: A controlled cross-sectional study. Hypertension 2013; 62: 331-336

[6] Bertacchini F, Paini A, Salvetti M et al. 9b.08: Cardiac and vascular damage in patients with primary aldosteronism and essential. Hypertension. J Hypertens 2015; 33: (Suppl 1): e122

[7] Hollenberg NK. Aldosterone in the development and progression of renal injury. Kidney Int 2004; 66: 1-9
[8] Aronova A, Fahey TJ III, Zarnegar R. Management of hypertension in primary aldosteronism. World J Cardiol 2014; 6: 227-233

[9] Hiramatsu K, Yamada T, Yukimura Y et al. A screening test to identify aldosterone-producing adenoma by measuring plasma renin activity. Results in hypertensive patients. Arch Intern Med 1981; 141: 1589-1593

[10] Mulatero P, Stowasser M, Loh KC et al. Increased diagnosis of primary aldosteronism, including surgically correctable forms, in centers from five continents. J Clin Endocrinol Metab 2004; 89: 1045-1050

[11] Tomaschitz A, Pilz S, Ritz E et al. Aldosterone and arterial hypertension. Nat Rev Endocrinol 2010; 6: 83-93

[12] Jiang SB, Guo XD, Wang HB et al. A retrospective study of laparoscopic unilateral adrenalectomy for primary hyperaldosteronism caused by unilateral adrenal hyperplasia. Int Urol Nephrol 2014; 46: 1283-1288

[13] Griffin AC, Kelz R, LiVolsi VA. Aldosterone-secreting adrenal cortical carcinoma. A case report and review of the literature. Endocr Pathol 2014; 25: 344-349

[14] Molina-Ayala M, Ramirez-Renteria C, Manguilar-Leon A et al. A rare presentation of primary hyperparathyroidism with concurrent aldosterone-producing adrenal carcinoma. Case Rep Endocrinol 2015; 2015: 910984

[15] Monticone S, Buffolo F, Tetti M et al. GENETICS IN ENDOCRINOLOGY: The expanding genetic horizon of primary aldosteronism. Eur J Endocrinol 2018; 178: R101-R111

[16] Mourtzinis G, Ebrahimi A, Gustafsson $\mathrm{H}$ et al. Aldosterone to renin ratio as a screening instrument for primary aldosteronism in a middle-aged population with atrial fibrillation. Horm Metab Res 2017; 49: 831-837

[17] Luo Q, Li NF, Yao XG et al. Potential effects of age on screening for primary aldosteronism. J Hum Hypertens 2016; 30: 53-61

[18] Bolignano D, Mattace-Raso F, Sijbrands EJ et al. The aging kidney revisited: A systematic review. Ageing Res Rev 2014; 14: 65-80

[19] Hannemann A, Friedrich N, Ludemann J et al. Reference intervals for aldosterone, renin, and the aldosterone-to-renin ratio in the population-based Study of Health in Pomerania (SHIP-1). Horm Metab Res 2010; 42: 392-399

[20] Fischer M, Baessler A, Schunkert H. Renin angiotensin system and gender differences in the cardiovascular system. Cardiovasc Res 2002; 53: 672-677

[21] Deng L, Xiong Z, Li H et al. Analytical validation and investigation on reference intervals of aldosterone and renin in Chinese Han population by using fully automated chemiluminescence immunoassays. Clin Biochem 2018. doi:10.1016/j.clinbiochem.2018.04.016:

[22] Pizzolo F, Raffaelli R, Memmo A et al. Effects of female sex hormones and contraceptive pill on the diagnostic work-up for primary aldosteronism. J Hypertens 2010; 28: 135-142

[23] Ahmed AH, Gordon RD, Ward G et al. Effect of combined hormonal replacement therapy on the aldosterone/renin ratio in postmenopausal women. J Clin Endocrinol Metab 2017; 102: 2329-2334

[24] Szmuilowicz ED, Adler GK, Williams JS et al. Relationship between aldosterone and progesterone in the human menstrual cycle. J Clin Endocrinol Metab 2006; 91: 3981-3987

[25] Fommei E, Ghione S, Ripoli A et al. The ovarian cycle as a factor of variability in the laboratory screening for primary aldosteronism in women. J Hum Hypertens 2009; 23: 130-135

[26] Ahmed AH, Gordon RD, Taylor P] et al. Are women more at risk of false-positive primary aldosteronism screening and unnecessary suppression testing than men? J Clin Endocrinol Metab 2011; 96: E340-E346

[27] Tiu SC, Choi CH, Shek CC et al. The use of aldosterone-renin ratio as a diagnostic test for primary hyperaldosteronism and its test characteristics under different conditions of blood sampling. J Clin Endocrinol Metab 2005; 90: 72-78 
[28] Brandenberger G, Follenius M, Muzet A et al. Ultradian oscillations in plasma renin activity: Their relationships to meals and sleep stages. J Clin Endocrinol Metab 1985; 61: 280-284

[29] Kerstens MN, Kobold AC, Volmer M et al. Reference values for aldosterone-renin ratios in normotensive individuals and effect of changes in dietary sodium consumption. Clin Chem 2011; 57: 1607-1611

[30] Koch M, Aker S, Haastert B et al. Clinical relevance of dietary salt intake on aldosterone and the aldosterone-to-renin ratio as screening parameters for primary aldosteronism. Clin Nephrol 2010; 74: 182-189

[31] Stowasser M, Ahmed AH, Pimenta E et al. Factors affecting the aldosterone/renin ratio. Horm Metab Res 2012; 44: 170-176

[32] Fischer E, Beuschlein F, Bidlingmaier $\mathrm{M}$ et al. Commentary on the endocrine society practice guidelines: Consequences of adjustment of antihypertensive medication in screening of primary aldosteronism. Rev Endocr Metab Disord 2011; 12: 43-48

[33] Duprez DA, De Sutter JH, De Buyzere ML et al. Renin-angiotensinaldosterone system, RR interval, and blood pressure variability during postural changes in borderline arterial hypertension. Am J Hypertens 1995; 8: 683-688

[34] Lamarre-Cliche M, de Champlain J, Lacourciere $Y$ et al. Effects of circadian rhythms, posture, and medication on renin-aldosterone interrelations in essential hypertensives. Am J Hypertens 2005; 18: 56-64

[35] Pilz S, Kienreich K, Gaksch M et al. Aldosterone to active Renin ratio as screening test for primary aldosteronism: Reproducibility and influence of orthostasis and salt loading. Horm Metab Res 2014; 46: 427-432

[36] Epstein M. Aldosterone and the hypertensive kidney: Its emerging role as a mediator of progressive renal dysfunction: A paradigm shift. J Hypertens 2001; 19: 829-842

[37] Brewster UC, Perazella MA. The renin-angiotensin-aldosterone system and the kidney: Effects on kidney disease. Am J Med 2004; 116: 263-272

[38] Lv LL, Liu BC. Role of non-classical renin-angiotensin system axis in renal fibrosis. Front Physiol 2015; 6: 117

[39] Barigou M, Ah-Kang F, Orloff E et al. Effect of postural changes on aldosterone to plasma renin ratio in patients with suspected secondary hypertension. Ann Cardiol Angeiol (Paris) 2015; 64: 169-174

[40] Catena C, Colussi G, Nadalini E et al. Relationships of plasma renin levels with renal function in patients with primary aldosteronism. Clin J Am Soc Nephrol 2007; 2: 722-731

[41] Ribstein ], Du Cailar G, Fesler P et al. Relative glomerular hyperfiltration in primary aldosteronism. J Am Soc Nephrol 2005; 16: 1320-1325

[42] Oelkers W, Diederich S, Bahr V. Primary hyperaldosteronism without suppressed renin due to secondary hypertensive kidney damage. J Clin Endocrinol Metab 2000; 85: 3266-3270

[43] Markou A, Sertedaki A, Kaltsas G et al. Stress-induced aldosterone hyper-secretion in a substantial subset of patients with essential hypertension. J Clin Endocrinol Metab 2015; 100: 2857-2864

[44] Seely EW, Conlin PR, Brent GA et al. Adrenocorticotropin stimulation of aldosterone: Prolonged continuous versus pulsatile infusion. J Clin Endocrinol Metab 1989; 69: 1028-1032

[45] Arvat E, Di Vito L, Lanfranco F et al. Stimulatory effect of adrenocorticotropin on cortisol, aldosterone, and dehydroepiandrosterone secretion in normal humans: Dose-response study. J Clin Endocrinol Metab 2000; 85: 3141-3146

[46] Whitworth JA, Butty J, Saines D et al. The effects of ACTH on the renin-aldosterone system in normotensive man. Clin Exp Hypertens A 1985; 7: 1361-1376

[47] Ahmed AH, Gordon RD, Ward G et al. Effect of Moxonidine on the Aldosterone/Renin Ratio in Healthy Male Volunteers. J Clin Endocrinol Metab 2017; 102: 2039-2043
[48] Seifarth C, Trenkel S, Schobel H et al. Influence of antihypertensive medication on aldosterone and renin concentration in the differential diagnosis of essential hypertension and primary aldosteronism. Clin Endocrinol (Oxf) 2002; 57: 457-465

[49] Mulatero P, Rabbia F, Milan A et al. Drug effects on aldosterone/plasma renin activity ratio in primary aldosteronism. Hypertension 2002; 40: 897-902

[50] Kondo T, Goto R, Sonoda K et al. Plasma renin activity and aldosterone concentration are not altered by the novel calcium channel antagonist, azelnidipine, in hypertensive patients. Intern Med 2010; 49: 637-643

[51] Jansen PM, van den Born BJ, Frenkel W] et al. Test characteristics of the aldosterone-to-renin ratio as a screening test for primary aldosteronism. J Hypertens 2014; 32: 115-126

[52] Ahmed AH, Gordon RD, Taylor P et al. Effect of atenolol on aldosterone/renin ratio calculated by both plasma Renin activity and direct Renin concentration in healthy male volunteers. J Clin Endocrinol Metab 2010; 95: 3201-3206

[53] Griffin TP, Browne GA, Wall D et al. A cross-sectional study of the effects of beta-blocker therapy on the interpretation of the aldosterone/renin ratio: Can dosing regimen predict effect? J Hypertens 2016; 34: 307-315

[54] Campbell DJ. Aliskiren therapy will have minimal effect on intracellular renin of renin-producing cells. Hypertension 2009; 53: e17 author reply e 18

[55] Campbell D], Nussberger ], Stowasser M et al. Activity assays and immunoassays for plasma Renin and prorenin: Information provided and precautions necessary for accurate measurement. Clin Chem 2009; 55: 867-877

[56] Snoep JD, Hovens MM, Pasha SM et al. Time-dependent effects of low-dose aspirin on plasma renin activity, aldosterone, cortisol, and catecholamines. Hypertension 2009; 54: 1136-1142

[57] Ahmed AH, Calvird M, Gordon RD et al. Effects of two selective serotonin reuptake inhibitor antidepressants, sertraline and escitalopram, on aldosterone/renin ratio in normotensive depressed male patients. J Clin Endocrinol Metab 2011; 96: 1039-1045

[58] Pizzolo F, Pavan C, Corrocher R et al. Laboratory diagnosis of primary aldosteronism, and drospirenone-ethinylestradiol therapy. Am J Hypertens 2007; 20: 1334-1337

[59] Locsei Z, Horvath D, Racz K et al. Progestin-dependent effect of oral contraceptives on plasma aldosterone/renin ratio. Clin Biochem 2012; 45: $1516-1518$

[60] Ahmed AH, Gordon RD, Taylor PJ et al. Effect of contraceptives on aldosterone/renin ratio may vary according to the components of contraceptive, renin assay method, and possibly route of administration. J Clin Endocrinol Metab 2011; 96: 1797-1804

[61] Quinkler M, Stewart PM. Hypertension and the cortisol-cortisone shuttle. J Clin Endocrinol Metab 2003; 88: 2384-2392

[62] Epstein MT, Espiner EA, Donald RA et al. Effect of eating liquorice on the renin-angiotensin aldosterone axis in normal subjects. Br Med J 1977; 1: 488-490

[63] Fischer E, Reuschl S, Quinkler M et al. Assay characteristics influence the aldosterone to renin ratio as a screening tool for primary aldosteronism: Results of the German Conn's registry. Horm Metab Res 2013; 45: 526-531

[64] Schirpenbach C, Seiler L, Maser-Gluth C et al. Automated chemiluminescence-immunoassay for aldosterone during dynamic testing: Comparison to radioimmunoassays with and without extraction steps. Clin Chem 2006; 52: 1749-1755

[65] Manolopoulou J, Fischer E, Dietz A et al. Clinical validation for the aldosterone-to-renin ratio and aldosterone suppression testing using simultaneous fully automated chemiluminescence immunoassays. J Hypertens 2015; 33: 2500-2511 
[66] Burrello ], Buffolo F, Monticone S et al. 9b.06: Comparison between Aldosterone and Renin Measurement by Chemiluminescent Immunoassay and Radioimmunoassay for the Diagnosis of Primary Aldosteronism. J Hypertens 2015; 33: (Suppl 1): e121

[67] Juutilainen A, Savolainen K, Romppanen J et al. Combination of LC-MS/ MS aldosterone and automated direct renin in screening for primary aldosteronism. Clin Chim Acta 2014; 433: 209-215

[68] Van Der Gugten JG, Dubland J, Liu HF et al. Determination of serum aldosterone by liquid chromatography and tandem mass spectrometry: A liquid-liquid extraction method for the ABSCIEX API-5000 mass spectrometry system. J Clin Pathol 2012; 65: 457-462

[69] Taylor P], Cooper DP, Gordon RD et al. Measurement of aldosterone in human plasma by semiautomated HPLC-tandem mass spectrometry. Clin Chem 2009; 55: 1155-1162

[70] Turpeinen U, Hamalainen E, Stenman UH. Determination of aldosterone in serum by liquid chromatography-tandem mass spectrometry. J Chromatogr B Analyt Technol Biomed Life Sci 2008; 862: 113-118

[71] Taylor PJ, Gordon RD, Stowasser M. Calibrators for measuring aldosterone by liquid chromatography-tandem mass spectrometry. Clin Chim Acta 2012; 413: 346-347

[72] Morganti A. European study group for the validation of DiaSorin LDRA. A comparative study on inter and intralaboratory reproducibility of renin measurement with a conventional enzymatic method and a new chemiluminescent assay of immunoreactive renin. J Hypertens 2010; 28: 1307-1312

[73] Rossi GP, Barisa M, Belfiore A et al. The aldosterone-renin ratio based on the plasma renin activity and the direct renin assay for diagnosing aldosterone-producing adenoma. J Hypertens 2010; 28: 1892-1899
[74] Glinicki P, Jeske W, Bednarek-Papierska L et al. The ratios of aldosterone/plasma renin activity (ARR) versus aldosterone/direct renin concentration (ADRR). J Renin Angiotensin Aldosterone Syst 2015; 16: 1298-1305

[75] Lonati C, Bassani N, Gritti A et al. Measurement of plasma renin concentration instead of plasma renin activity decreases the positive aldosterone-to-renin ratio tests in treated patients with essential hypertension. J Hypertens 2014; 32: 627-634

[76] Unger N, Lopez Schmidt I, Pitt C et al. Comparison of active renin concentration and plasma renin activity for the diagnosis of primary hyperaldosteronism in patients with an adrenal mass. Eur J Endocrinol 2004; 150: 517-523

[77] Ducher M, Mounier-Vehier C, Baguet JP et al. Aldosterone-to-renin ratio for diagnosing aldosterone-producing adenoma: A multicentre study. Arch Cardiovasc Dis 2012; 105: 623-630

[78] Perschel FH, Schemer R, Seiler L et al. Rapid screening test for primary hyperaldosteronism: Ratio of plasma aldosterone to renin concentration determined by fully automated chemiluminescence immunoassays. Clin Chem 2004; 50: 1650-1655

[79] Phillips JL, Walther MM, Pezzullo JC et al. Predictive value of preoperative tests in discriminating bilateral adrenal hyperplasia from an aldosterone-producing adrenal adenoma. J Clin Endocrinol Metab 2000; 85: 4526-4533

[80] Berge C, Courand PY, Harbaoui B et al. Decreased plasma prorenin levels in primary aldosteronism: Potential diagnostic implications. J Hypertens 2015; 33: 118-125 